\title{
Teatro e Política: Uma Redescoberta do Prazer DA HISTÓRIA
}

Sandra de Cássia A. Pelegrini*

Resumo: Este artigo procura discutir a importância da arte dramática no estudo da história, enquanto um dinâmico recurso didático que pode ser equacionado no primeiro, segundo e terceiro graus.

Unitermos: teatro, ensino de história, cidadania e arte.

Nos últimos 30 anos, os debates em tomo da educação têm buscado novos referenciais, instrumentos pedagógicos e filosóficos. $\mathrm{O}$ eixo das discussões aparece centrado na possibilidade de se criar uma pedagogia voltada para uma prática educacional de formação crítica do indivíduo em relação ao contexto em que se insere.

No campo da História, preservadas as especificidades de cada estado ou região, esse debate tem assumido um caráter multifacetado. Se nos anos 70 , a legislação educacional aprisionava o conhecimento histórico nas grades disciplinares da Educação Moral e Cívica e dos Estudos Sociais; nos anos 80, a proposta curricular para o Ensino de História (I Grau) evocava um lugar diferenciado, um espaço de pesquisa fundamentada na criatividade e autonomia (SILVA, 1995:123).

Em que pese a proficua reflexão suscitada pela experiência no âmbito da organização de determinados eixos temáticos, conectados à vivência dos próprios alunos, nos anos 90 tem se delineado uma

- Professora do Departamento de História - Universidade Estadual de Maringá Maringá/PR. 
PELEGRINI, S. C. A. Teatro e Politica.

situação que em última instância parece legitimar um divisor de águas entre ensino e pesquisa.

Embora não preconize o reordenamento de antigos conteúdos, o Curriculo Básico para Escola Pública do Estado do Paraná parece não oferecer condições para que professores e alumos possam subverter uma relação passiva frente ao passado, questionando-o a partir de uma imprescindivel relação com o presente.

A despeito das dificuldades para viabilizar uma efetiva reformulação do ensino - afinado aos debates contemporâneos, o Currículo Básico parece não ter conseguido ervolver satisfatoriamente a maioria dos professores da Rede, aqueles que têm a incumbência de materializar a proposta em sala de aula (Dias, 1995: 52-53).

Todavia, não é isso que o Plano de Ação - Gestão 1995-1998 e Diretrizes do Plano de Capacitação Permanente, divulgados pela Secretaria de Estado da Educação do Paraná, deixam transparecer. Em linhas gerais, esses documentos apontam para uma gestão compartilhada e um movimento no sentido de fazer acontecer uma mudança no cerne da escola, bem como, na relação que a escola estabelece com a sociedade na qual se insere. Tais mudanças estariam pautadas na promoção da excelência da educação.

No Plano de Ação vê-se explicitada:

O que importa é sabermos onde desejamos chegar, para contribuir na construção de uma sociedade mais fraterna, sem preconceitos e sempre pluralista, comprometida com a justiça e a produção do conhecimento cumulativo $e$ compartilhado entre todos (SEED, $1995,7)$

Com vistas a atingir este gênero singular de produção do conhecimento, a Secretaria de Estado da Educação se propõe a garantir acesso ao programa de capacitação permanente a todos os profissionais da educação e a ampliação das parcerias com as 
Instituições de Ensino Superior para a oferta de cursos nas diversas áreas do conhecimento (SEED, 1995: 14)

Em termos práticos, o que se observa é uma crônica falta de recursos financeiros e materiais e uma imensa dificuldade para viabilização de cursos que não se circunscrevam à perspectiva da reciclagem de conteúdos para os professores de I e II graus, nem se limitem a um breve trabalho executado no período de férias escolares.

No âmbito dessas preocupações, surgiu o projeto de extensão intitulado O fazer teatral: arte, história e cidadania', fruto da junção de experiências diferenciadas, mas que tinham em comum a perspectiva de articular o universo teórico da história com a prática teatral. Pensando na possibilidade de superar o cárcere que insiste em restringir a atividade docente ao espaço da universidade, essa proposta visava uma prática pedagógica voltada para o fomento cultural, e também, uma maior aproximação entre universidade, escolas de I e II graus e a comunidade ${ }^{2}$

Fundamentado nos escritos de Paulo Freire, o projeto aventurou-se pelos caminhos de uma educação menos tradicional. E, embora com grau de utopia menor que a chamada pedagogia libertadora, essa proposta mantinha-se arraigada ao compromisso de resgatar na relação educador-educando-conhecimento, um processo de aprendizado recíproco, cujo pressuposto básico assentava-se no entendimento de que o educando não é um receptacúlo de informações, pelo contrário, é um agente ativo, capaz de problematizar a história e o saber.

\footnotetext{
'Esse projeto foi idealizado por mim, pelo acadêmico Newdemar A. Freitas de Souza e pelo professor Wesley Delconti (Escola Estadual de I Grau Ariovaldo Moreno). Contou com o apoio do Diretório Central dos Estudantes/UEM, PróReitoria de Extensão e Cultura e Diretoria de Extensão (que contemplou o acadêmico com uma bolsa de extensão de 48 horas mensais).

${ }^{2}$ A princípio, o projeto estaria aberto aos alunos do II grau e para os acadêmicos do curso de história e áreas afins, no entanto, acabou incorporando alumos dos cursos de química, direito e psicologia, e também, um professor da rede de ensino público de Maringá e alunos do l e ll Graus da rede pública de ensino dessa cidade .
} 
A educação libertadora, do ponto de vista de Freire(1980:29), tem a responsabilidade de desvendar as amarras impostas pela educação tradicional, possibilitando ao educando a conscientização. $\mathrm{Em}$ outros termos, tal ação implicaria em tomar posse da realidade, e consequentemente, a concretização produziria a desmistificação das relações sociais, políticas e culturais.

A técnica de Freire 1 1978: 15-16), possibilitava o dominio da leitura e da escrita e permitia que os conteudos culturais inerentes ao processo de alfabetização se voltassem para o exame crítico de problemas concretos.

Nessa direção, a linha mestra do projeto apontava para a tentativa de trabalhar o teatro enquanto um experimento educacional, capaz de propiciar a problematização do saber, dos conteudos históricos e da realidade sócio-cultural dos indivíduos.

A prática teatral diretamente vinculada ao presente projeto de extensão, estava sendo equacionada como agente fomentador $e$ problematizador da sociedade; como um meio pedagógigo em construção, no qual seria possivel processar a desmistificação da realidade construida pela cultura dominante, ampliar os horizontes e o senso crítico dos individuos. e tomar esse espaço aberto a discussão dos problemas e das conquistas humanas.

Por certo as formas de organização da arte dramática envolvem uma dada ação cultural. Esta, por sua vez, pode voltar-se para uma ação libertadora ou para ação domesticadora, enquanto a primeira prima pelo diálogo e tematiza problemas, a segunda procura embotar as consciências e slogarizar as conjunturas (Freire, 1982: 81).

... a educação ou a ação cultural para a libertação, em lugar de ser aquela alienante transferência de conhecimento. é o autêntico ato de conhecer, em que os educandos - também os educadores como consciências intencionadas ao mundo ou como corpos conscientes, se inserem com os educadores - educandos também " na busca de novos 
PELEGRINI, S. C. A Teatro e Política.

conhecimentos, como consequência do ato de reconhecer o conhecimento existente ... (Freire, 1982: 99)

Desta forma, entendeu-se que a educação voltada para a cidadania envolvia a percepção daquilo que estava implicito no individuo e na sua relação com o mundo - algo que embora não fosse explicitado poderia ser trabalhado pela prática pedagógica associada a linguagem teatral, seus jogos lúdicos e exercícios dramáticos.

Por esse viés pretendia-se articular a problemática inserida nos embates e contrapontos referentes a arte-história-política.

Evidentemente, a essência dessa proposta não podia deixar de passar pelo crivo do debate travado em praça pública acerca da universalidade da cultura e suas relações com a educação e a política.

Entendendo que existe na sociedade um movimento constante de circulação de idéias e que a organização do real no imaginário humano não se limita apenas às ações e valores impostos pela classe dominante, buscou-se trabalhar as práticas do teatro enquanto expressão diversificada e plural.

Em outras palavras, essa postura implicava na percepção de que na fala do teatro, assim como na expressão de outras práticas culturais, poderia ser detectada, por um lado, a assimilação do discurso da ideologia dominante, e por outro, o processo de sua negação.

Contudo, haveria que ficar claro que numa época onde a essência da relação entre cultura e sociedade é permeada pela massificação dos valores, evidenciar-se-ia também uma relação entre arte e política, entre produto cultural e sociedade de massa (Chaui, 1984:90).

Além disso, haveria necessidade de atentar para o fato de que a cultura na sociedade contemporânea caminha, lado a lado, com sua subordinação à funcionalidade. E, que a redução da arte ou da política a determinados fins leva à sua banalização, ou seja, à redução do seu campo de ação às exigências do consumo. Assim, tornava-se importante perceber que a arte e a política, não obstante seus conflitos e tensões, se inter-relacionam e até são dependentes (Arendt, 1972).

Do ponto de vista didático, tornava-se imprescindivel lançar mão de uma fundamentação teórica que desse conta de viabilizar o ensino 
PELEGRINI, S. C. A. Teatro e Politica.

da História através da arte dramática. Nesse campo, a referência que deveria anteceder a explicação da utilização do teatro e de textos dramáticos como recursos para a história, remetia ao entendimento da arte como processo social, no qual a construção de certas imagens expressavam determinadas visões de mundo (Fabris, 1985: 40).

Portanto, a produção artística - portadora de valores sociais intrínsecos e cargas de significação resultantes da interação com o seu cotidiano, poderia ser tratada como um documento histórico ${ }^{3}$. E, como tal, deveria ser cotejado ao discurso sócio-político de uma época especifica. Assim, as peças de teatro poderiam constituir uma valiosa altemativa metodológica para o ensino de História e um exercício prazeiroso de discussão da cidadania.

Desse modo, o projeto propunha um estudo, ainda que superficial, sobre as trajetórias do teatro político no Brasil, privilegiando a contemporização de determinados textos dramáticos à algumas fases da conjuntura politico-social do país.

Nesses termos, o trabalho se organizou a partir de três módulos ${ }^{4}$. No primeiro, seria privilegiada a discussão acerca dos caminhos trilhados pelo teatro, suas propostas e prerrogativas. No segundo, seriam estudas problemáticas pertinentes ao teatro contemporâneo, que abordam desde as reviravoltas do teatro político até as críticas às concepções burguesas de teatro. No terceiro e último módulo, centrariamos a atenção em textos específicos como Eles não usam Black-Tie e A Semente de F. Guamieri, O Rei da Vela de Oswald de Andrade, Calabar de Chico Buarque de Hollanda e Amor em campo minado de Dias Gomes.

Por certo, o projeto não conseguiu esgotar os textos propostos, nem tão pouco explorar de modo globalizante as temáticas neles inseridas.

A leitura deste documento diferenciado exige certos cuidados técnicos por parte do historiador, na medida em que seu conteúdo só pode ser apreendido a partir de suas próprias leis - estética, linguagem, estrutura intema, simbologia.

4 o curso previa 120 horas/aula, distribuidas em quarenta encontros com carga horária de 3 horas. 
PELEGRINI, S. C. A Teatro e Politica.

No entanto, vale resgatar aqui de que forma se pretendeu articular o ensino de história, arte e cidadania.

\section{Dramaturgia e teatralização - uma alternativa para o ensino de História}

Partindo do pressuposto, segundo o qual, o texto dramático, assim como o filme, é um campo de estudo privilegiado para o historiador, procuravamos contextualizar as referidas obras na época em que foram produzidas e depois passamos a tematizar algumas questões sugeridas por elas, mas que, de modo geral, extrapolavam as problemáticas inerentes ao seu tempo.

Tomando, por exemplo, a peça Eles não usam black-tie - que também foi convertida num dos filmes do cinema nacional, seria possivel tematizar aspectos da realidade brasileira.

Embora Black-tie apresente uma visão romântica e idealizada do mundo, atribuindo uma função social e um papel de destaque à consciência enquanto ordenação natural das coisas; aponta problemas vivenciados pela classe operária, o conflito de diferentes interesses de classes sociais, a atuação política dos trabalhadores e a vida na favela.

A greve por melhoria salarial constitui o eixo da trama, a partir dela são arroladas outras questões que levariam a uma cisão entre pai $e$ filho, ambos empregados na mesma fábrica. O personagem Otávio é um operário revolucionário, consciente da força de sua classe e um dos líderes do movimento grevista. Tião, seu filho, opõe-se a deflagração da greve e trai a classe operária, na medida em que questiona a positividade dessa ação e acaba primando por seus interesses individuais - que na verdade se circunscrevem à necessidade de subsistência.

Tal posição é interpretada no texto, por um lado, como um reflexo do medo da pobreza, uma tentativa de escapar da condição de miserabilidade do operariado. E, por outro, como uma deformidade ideológica inerente às condições em que o personagem fora criado. Em outros termos, o enredo sugere que as condições do meio moldam o indivíduo, que, por sua vez, não é de todo mau. Esta perspectiva HISTÓRIA \& ENSINO, Londrina, 02: 69-79, 1996 
PELEGRINI, S. C. A. Teatro e Politica.

aparece claramente no diálogo entre Otávio e Tião, quando o pai toma para si a responsabilidade pela má formação do filho - criado distante da autêntica vida da favela, por tios de classe média (Guamieri, 1958: 99).

A forma como o conflito entre o interesse coletivo e o individual é apresentada propõe uma reflexão que transcende a problemática inicial: a realidade imediata de cada um se confronta com o sonho da sociedade bem organizada, se distancia dos ideais de greve e revolução apontados como meios de alcançar uma vida melhor. Do ponto de vista de Tião, oposto ao de Otávio, a mulher grávida e a miséria representavam problemas imediatos que o impulsionavam a pronunciar-se contra a greve. $O$ sentimento de Tião é expresso no seguinte diálogo com o operário Jesuíno:

.. Eu to fazendo isso consciente. Único jeito que tenho é me arrumá, não devo satisfação pra ninguém. Quem quisé que se arrebente de fazé greve a vida toda por causa de mixaria. Eu não sou disso. Quero casá e vivê fehiz com minha mulhé! Se a turma quisé, pode dá o desprezo..(Guarnieri, 1958: 63).

Romana, mãe de Tião, medeia o conflito. A sua postura franca e realista diante dos problemas intervém no sentimentalismo das posiçóes defendidas pelo filho e pelo companheiro, dando à discussão a dimensão cotidiana do mundo do morro. Porém, no final da trama ela reconhece os descaminhos da mentalidade do filho e conclui que eles poderiam ser corrigidos através da recondução do fillho a sua classe de origem.

A solução apresentada pelo drama à vida difícil do operariado é a união em tomo de objetivos comuns e o despertar da alienação. Diante do momento da partida de Tião, com perspicácia e paixão política, Otávio revela: Enxergando melhó a vida, ele volta.

Em termos estéticos, essa peça exterioriza não apenas o conflito de gerações, o confronto entre capital e trabalho, mas principalmente, uma revisão da linguagem teatral brasileira. A nova linguagem cênica 
PELEGRINI, S. C. A. Teatro e Politica.

voltava-se para a tentativa de apresentar sem retoques o cotidiano da maior parte da população, negava-se a destacar apenas seus aspectos exóticos ou pitorescos. Mostrava as tradições populares do morro, as maselas de seus habitantes, o operário dividido entre os seus problemas mais imediatos e o ideal revolucionário.

No âmbito político, o texto de Guarnieri denota o prelúdio da arte que nos anos sessenta seria designada arte popular revolucionária, portadora de alcance histórico e trânsito no campo da emancipação gradual da sociedade - almejada pela militância de esquerda. Aspecto extremamente relevante, considerando-se que durante o Governo de João Goulart, cresciam no Brasil movimentos de masssa e estavam em evidência inúmeros esforços no sentido de promover a educação e a cultura, levados a termo pelos Movimentos de Educação de Base (Igreja Católica), Centros Populares de Cultura (União Nacional dos Estudantes), entre outros. Estava também em curso no pais uma intensa mobilização em pról da efetivação das Reformas de Base - nos setores agrário, fiscal, administrativo e educacional (Toledo, 1991: 17 32).

Metodologicamente, a organização das leituras dinâmicas e interpretação dos textos selecionados se dava a partir de grupos dirigidos de trabalho - técnica que tornava essa experiência de ensinoaprendizagem muito mais prazeirosa, e simultaneamente, mais profunda.

As pessoas não apenas socializavam suas impressões sobre as personagens e suas temáticas, como também, passavam a articulá-las às experiências vivenciadas direta ou indiretamente por elas.

O manuseio das peças e o ato de dramatizar alguns de seus trechos ou passagens, tornava mais fácil compreender determinados periodos $\mathrm{e}$ problemáticas da História do Brasil, concretizando pensamentos e expressando certas percepções de mundo e suas significações.

A interação entre questões da história, da arte e da cidadania figurou como um elo de ligação entre passado e presente, exercicio que culminou com um proficuo desenvolvimento de uma oficina de teatro, a 
PELEGRINI, S. C. A. Teatro e Politica.

criação da Companhia Corpo e um grupo de estudos em defesa dos direitos humanos ${ }^{5}$.

Enfim, ao considerarmos o fazer teatral como um espaço privilegiado do debate cultural e político, tomou-se possivel pensá-lo enquanto cenário de discussões relacionado às diversas práticas humanas.

A despeito de todas as dificuldades - falta de recursos materiais e audio-visuais, e dos tropeços metodológicos emergentes no decorrer da execução desse projeto, houve um movimento de aprendizado recíproco e de alargamento das experiências individuais. $E$ mais, através desse projeto foi possivel redescobrir o prazer da História e a viabilidade de alternativas didáticas, que em última instância, visavam uma maior aproximação entre o ensino universitário e o ensino de primeiro e segundo graus, e ainda, a simultaneidade entre ensino, pesquisa e extensão.

\section{Referências Bibliográficas}

ARENDT, Hannah. Entre o passado e o futuro. São Paulo: Perspectiva, 1972.

BOAL, Augusto. Técnicas Latino-Americanas de Teatro Popular. São Paulo: Brasiliense, 1984.

CHAUI, Marilena. Conformismo e resistência - aspectos da cultura popular no Brasil, São Paulo: Brasiliense, 1986.

DIAS, Reginaldo. "A Implementação do novo currículo de história na rede de ensino do Paraná: reflexões de um colaborador". História \& Ensino. Londrina: Laboratório de Ensino de História/UEL, 1995.

5 Com a iniciativa e o apoic de Newdemar de Souza e Wesley Delconti acadêmicos que atuam profissionalmente no teatro maringaense e na rede pública de ensino, a Companhia Corpo empreendeu a montagem de um espetáculo organizado a partir da interpretação de poesias de Carlos Drumond de Andrade - textos que foram escolhidos por iniciativa dos participantes do projeto, apresentado ao público no Teatro Oficina da UEM e no Teatro Barracão, em Maringá/Paraná 
FABRIS, Ana Teresa. "História e Arte: a História em busca de novas linguagens". Proje to História, n.4. São Paulo: EDUC, 1985.

FREIRE, Paulo. 6a . ed. Ação cultural para a liberdade e outros textos. Rio de Janeiro: Paz e Terra, 1982.

FREIRE, Paulo. $3^{a}$. ed Conscientização - Teoria e Prática da Libertação. São Paulo: Ed. Moraes 1980.

GUARNIERI, G. Eles não usam black-tie. Rio de Janeiro: Civilização Brasileira, 1978

KHUNER, Maria Helena. Teatro popular: uma experiência. São Paulo: Francisco Alves, 1975.

PEIXOTO, Fernando. $O$ que é teatro. São Paulo: Nova Cultural, 1986.

PELEGRINI, Sandra de Cássia A. "Os anos 60: um projeto politicocultural em debate", História. São Paulo: Unesp, 1991

SECRETARIA DE ESTADO DE EDUCAÇAO DO PARANA. Curriculo Básico para a Escola Pública do Estado do Paraná. Curitiba: SEED, 1990.

Reestruturação do ensino de Segundo Grau no Paraná. Curitiba: SEED, 1993.

Plano de Ação - Gestão 1995-1998. Curitiba: SEED, 1995.

Diretrizes do Plano de Capacitação Permanente. Curitiba: SEED, 1995.

SILVA, Marcos A. "Histórias para o ensino". SILVA, Zélia Lopes da.(org.) Cultura Histórica em debate. São Paulo: Editora da Universidade Estadual Paulista, 1995.

TOLEDO, Caio Navarro de. O Governo Goulart e o Golpe de 64. São Paulo: Brasiliense, 1991. 